J. Clin. Chem. Clin. Biochem.

Vol. 28, 1990, pp. $241-250$

(C) 1990 Walter de Gruyter \& Co.

Berlin · New York

\title{
Mutations of the Mitochondrial DNA: The Contribution of DNA Techniques to the Diagnosis of Mitochondrial Encephalomyopathies
}

\author{
By K.-D. Gerbitz ${ }^{1}$, B. Obermaier-Kusser ${ }^{1}$, P. Lestienne ${ }^{2}$, S. Zierz ${ }^{3}$, J. Müller-Höcker $^{4}$, D. Pongratz ${ }^{5}$, \\ Ingrid Paetzke-Brunner ${ }^{1}$ and T. Deufel ${ }^{6}$ \\ ${ }^{1}$ Institut für Klinische Chemie und Institut für Diabetesforschung \\ Städt. Krankenhaus Schwabing, München, Germany \\ 2 INSERM U298 Centre Hospitalier Régional d'Angers, Angers, France \\ ${ }^{3}$ Neurologische Universitätsklinik, Bonn, Germany \\ ${ }^{4}$ Pathologisches Institut der Universität, München, Germany \\ ${ }_{5}^{5}$ Friedrich-Baur-Institut an der Universität, München, Germany \\ ${ }^{6}$ v. Haunersches Kinderspital der Universität, München, Germany
}

(Received September 4, 1989/January 29, 1990)

\begin{abstract}
Summary: We performed restriction analysis and Southern blotting of the muscle mitochondrial DNA from 34 patients suffering from different myopathies. In 13/21 patients with chronic progressive external ophthalmoplegia the muscle mitochondrial DNA was shown to be heteroplasmic. Further mapping by use of several restriction enzymes yielded large deletions in muscles from 10/13 chronic progressive external ophthalmoplegia patients. Most of the deletions spanned large parts of the mitochondrial genome, leading to loss of mitochondrial genes encoding several subunits of the respiratory chain complexes I (NADH-dehydrogenase), IV (cytochrome c oxidase) and V (ATP-synthetase), as well as of several tRNAs.
\end{abstract}

Comparison of the mapping data with the histochemical and biochemical results did not provide a clear correlation between the location of the mitochondrial genetic defects and the functional deficiencies of the affected respiratory chain complexes.

In the majority of patients with chronic progressive external ophthalmoplegia, but without a family history of the disease, restriction analysis reveals large mutations of the mitochondrial genome, while other methods are necessary for the localization of defects in all cases with maternal transmission of the disease. The same holds true for all other kinds of mitochondrial myopathies based on defects within the nuclear DNA or on derangements of the "cross-talk" between the nuclear and the mitochondrial genomes.

\section{Introduction}

The most important function of mitochondria is the production of energy in the form of ATP by oxidative phosphorylation via the respiratory chain. As this is an essential requirement for the survival and health of nearly all cells, defects in the energy providing machinery of the mitochondrion lead to disease. Depending on the number of affected cells, the type of organ and the affected metabolic pathway, the sever- ity of the resulting diseases can range from only slight and discrete forms to those with a lethal outcome. The variability of the diseases often renders the dif. ferential diagnosis difficult. In most congenital or infantile forms of the mitochondrial disorders the leading symptom is lactic acidosis due to an interruption of substrate utilisation within the mitochondrion. Usually the predilection locus of the disease is the skeletal muscle, leading to a classification of these 
forms as mitochondrial myopathies. In adult forms, discrete parts of the central nervous system are frequently affected and neuromuscular symptoms are the first indicators. Therefore as an important diagnostic step a muscle biopsy is taken and the tissue is subjected to histological, histochemical, electron microscopical and biochemical investigations.

Recently Holt, Harding \& Morgan-Hughes (1) discovered a new diagnostic approach when they found deletions of the mitochondrial DNA (mtDNA) in some patients with mitochondrial myopathies. The five respiratory chain complexes are composed of 69 polypeptide subunits, 13 of them encoded by the mitochondrial genome. Since many metabolic pathways are also located specifically within the mitochondrion, the potential number of defects at different sites within the mitochondrion is very large. Thus a detailed classification of the diseases requires the application of many different methods. On the other hand, the amount of muscle tissue usually obtained by biopsy is very limited. Therefore, in order to increase the probability of defect localisation, an adequate diagnostic strategy is necessary, which takes account of the different diagnostic valencies of the methods used.

Here we describe restriction fragment analysis of muscle biopsies from 34 patients with different myopa- thies, and the results are compared with the histochemical and biochemical data. In some cases genomic Southern blotting was also performed in cultured fibroblasts from affected patients. In addition, we have developed a scheme for an efficient diagnostic procedure for mitochondrial myopathies, taking into account the work so far reported on mtDNA deletions $(1-12,38)$.

\section{Materials and Methods}

\section{Patients}

The 34 patients were divided into four groups.

Group 1 (patients $1-5$ of tab. 1) consisted of 5 patients suffering from typical Kearns-Sayre syndrome, i.e. chronic progressive external ophthalmoplegia, pigmentary retinopathy, heart block and at least one of the following symptoms: limb weakness, ataxia and/or other neurological symptoms.

Group 2 (patients 6-21 of tab. 1) consisted of 16 patients with ocular myopathy including ptosis and ophthalmoplegia; most of them had an additional symptom like limb weakness, ataxia and/or peripheral neuropathy.

Group 3 (patients 22-26 of tab. 1) consisted of 5 patients with histochemically and biochemically defined mitochondrial myopathies; all had lactic acidosis; one had mitochondrial encephalomyopathy with lactic acidosis and stroke-like episodes (patient 22); 2 had fatal infantile cytochrome c oxidase deficiency (patients 23, 24); one had a combined complex I and IV deficiency (patient 25), and one (patient 26) had muscular carnitine deficiency.

Tab. 1. Clinical data of patients with chronic progressive external ophthalmoplegia (group 1,2)

\begin{tabular}{|c|c|c|c|c|c|c|c|c|c|c|}
\hline \multirow[t]{2}{*}{ Patient no. } & \multirow[t]{2}{*}{ Sex } & \multirow{2}{*}{$\begin{array}{l}\text { Age } \\
\text { (a) }\end{array}$} & \multirow{2}{*}{$\begin{array}{l}\text { Age of } \\
\text { onset } \\
\text { (a) }\end{array}$} & \multicolumn{6}{|c|}{ Clinical symptoms } & \multirow{2}{*}{$\begin{array}{l}\text { Ragged } \\
\text { red } \\
\text { fibres }\end{array}$} \\
\hline & & & & $\begin{array}{l}\text { Chronic } \\
\text { progressive } \\
\text { external } \\
\text { ophthal- } \\
\text { moplegia }\end{array}$ & $\begin{array}{l}\text { Retinitis } \\
\text { pigmentosa }\end{array}$ & $\begin{array}{l}\text { Heart } \\
\text { block }\end{array}$ & $\begin{array}{l}\text { Limp } \\
\text { weakness }\end{array}$ & Ataxia & $\begin{array}{l}\text { Other } \\
\text { neurological } \\
\text { symptoms }\end{array}$ & \\
\hline
\end{tabular}

\begin{tabular}{llll}
\hline Group 1 & & & \\
1 & $q$ & 33 & 13 \\
2 & + & 51 & 20 \\
3 & वे & 45 & 30 \\
4 & + & 36 & 17 \\
5 & o & 26 & 11
\end{tabular}

Group 2

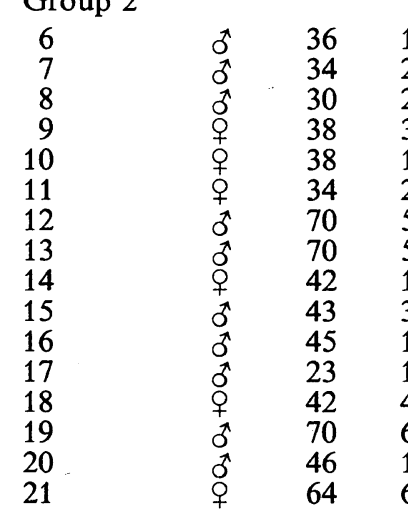

13
20
30
17
11

$\begin{array}{ll}+ & + \\ + & + \\ + & + \\ + & +\end{array}$

+
+
+
+
+

+
+
+
+

+
+
-

+
+
+

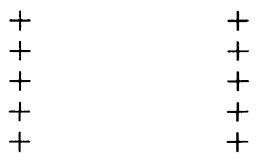

17
21
20
30
12
28
58
55
16
37
18
19
42
68
11
62

$\begin{array}{ll}+ & \\ + & \\ + & \\ + & \\ + & \\ + & \\ + & - \\ + & - \\ + & - \\ + & - \\ + & \\ + & \\ + & \\ + & \end{array}$

\begin{tabular}{c}
$\vdots$ \\
$\vdots$ \\
$\vdots$ \\
$\vdots$ \\
$\vdots$ \\
$\vdots$ \\
$\vdots$ \\
\hline \\
\hline
\end{tabular}

-
-
-
-
-
-
-
+
-
-
-
-

$\begin{array}{ll}+ & - \\ - & - \\ - & - \\ + & - \\ + & - \\ + & - \\ + & + \\ + & - \\ - & + \\ - & - \\ - & - \\ - & - \\ - & - \\ + & -\end{array}$

$\begin{array}{ll}- & + \\ - & + \\ - & + \\ - & + \\ - & + \\ - & + \\ + & + \\ - & + \\ - & + \\ + & + \\ - & + \\ - & + \\ + & + \\ - & +\end{array}$


For all patients of groups 1,2 and 3, histological examination of skeletal muscle revealed ragged red fibers.

Group 4 consisted of 8 patients (not shown in tab. 1) suffering from different forms of degenerative myopathies. None of them had chronic progressive external ophthalmoplegia or ragged red fibers in their skeletal muscle; no histochemical/biochemical respiratory chain complex deficiency was observed.

\section{Muscle biopsy and morphology}

Muscle biopsies (approximately $750 \mathrm{mg}$ wet weight per biopsy) were obtained from patients under local anaesthesia. For histochemical analysis muscle specimens were immediately frozen in isopentane cooled in liquid nitrogen. Histological and histochemical routine procedures included a modified Gomori trichrome stain and reactions for NADH-tetrazolium reductase (complex I), succinate dehydrogenase (complex II), cytochrome c oxidase (complex IV) and mitochondrial ATP-synthetase (complex V) (13).

\section{Muscle homogenate}

Frozen muscle was homogenized with 29 volumes of $50 \mathrm{mmol} / 1$ TRIS- $\mathrm{HCl}$, pH 7.4 containing $150 \mathrm{mmol} / \mathrm{K} \mathrm{KCl}$ and $1 \mathrm{mmol} / \mathrm{l}$ EDTA by use of a glass/glass homogenizer. The homogenate was filtered through two layers of cheese cloth to remove connective tissue (14).

\section{Biochemistry}

Activities of NADH-cytochrome c oxidoreductase were measured spectrophotometrically in muscle homogenates as described by Hatefi \& Rieske (15). The activity of complex I + III was determined as the antimycin $\mathrm{A}$ and rotenone sensitive fraction of total NADH-cytochrome c oxidoreductase in the presence of antimycin $A(5 \mathrm{mg} / \mathrm{l})$ and rotenone $(5 \mathrm{mg} / \mathrm{l})$. Succinate-cytochrome c oxidoreductase (complex II + III) was measured as described by Tisdal (16), succinate dehydrogenase (part of complex II) as described by Hatefi \& Stiggal (17), and cytochrome c oxidase (complex IV) as described by Wharton \& Tzagaloff (18). Citrate synthase was measured as described by Sheperd \& Garland (19) in the presence of $40 \mathrm{ml} / 1$ Triton.

\section{DNA analysis}

Proteinase $\mathrm{K}$, restriction enzymes and the nick-translation kit were from Boehringer Mannheim, $\left[\alpha^{32} \mathrm{P}\right] \mathrm{dCTP}(111 \mathrm{TBq} / \mathrm{mmol}$ $=3000 \mathrm{Ci} / \mathrm{mmol}$ ) from NEN and Hybond $\mathrm{C}$ filters were from Amersham, Germany. Agarose was from Bethesda Research Laboratories (BRL), and chemicals were from Sigma or from Merck, Germany.

The DNA from $30-50 \mathrm{mg}$ of tissue was extracted by overnight digestion with $200 \mathrm{mg} / \mathrm{l}$ of proteinase $\mathrm{K}$ in $1 \mathrm{ml}$ of $10 \mathrm{mmol} / 1$ Tris-HCl, $\mathrm{pH} 8.0,400 \mathrm{mmol} / 1 \mathrm{NaCl}, 2 \mathrm{mmol} / 1$ EDTA, 2 g/l SDS at $37^{\circ} \mathrm{C}$. DNA was recovered by extraction with phenol, phenol/chloroform, precipitated with 2 volumes of ethanol and $100 \mathrm{mmol} / 1 \mathrm{NaCl}$, and dissolved in $60 \mu \mathrm{l}$ of $25 \mathrm{mmol} / 1 \mathrm{Tris}-$ $\mathrm{HCl}, 1 \mathrm{mmol} / 1$ EDTA $\mathrm{pH} 8.0$.

DNA $(0.5 \mu \mathrm{g})$ was digested with the endonucleases BamHI, PvuII, PstI, HindIII, HpaI, EcoRV, XbaI, KpnI and AvaII as described (20), then separated by electrophoresis $(8 \mathrm{~V} / \mathrm{cm}$ for $5 \mathrm{~h}$ ) on an $8 \mathrm{~g} / \mathrm{l}$ agarose gel, stained with $0.1 \mathrm{mg} / 1$ ethidium bromide for $15 \mathrm{~min}$ and subjected to Southern blotting.

The mitochondrial DNA probes used for hybridization are described in detail elsewhere (12).

\section{Results and Discussion}

\section{Preliminary Remarks}

Besides its nuclear genome the cell contains up to several thousand copies of the mtDNA. The mitochondrial genome is double-stranded and circular, unlike the nuclear DNA, which is linear. The 16569 base pair mtDNA constitutes genes that code for 13 subunits of the respiratory chain complexes, 22 tRNAs and 2 rRNAs (22). As compared with nuclear DNA, the mitochondrial genome has a highly compact structure consisting almost entirely of coding regions (fig. 1), and it uses its own genetic code. It is inherited exclusively from the mother and can segregate during mitotic growth. Mitochondrial DNA shows a high mutation rate, yet encodes highly conserved proteins. Because of these traits, analysis of the mtDNA mutations has yielded new insights into the inheritance and the appearance of some neuromuscular defects (23).

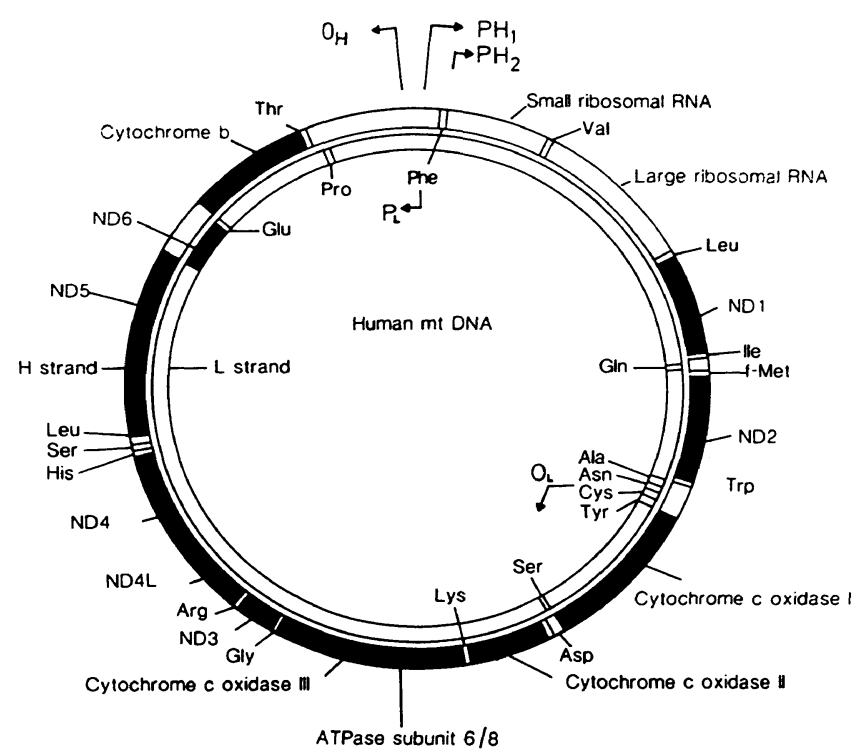

Fig. 1. Mitochondrial DNA according to 1.c. $(22,23)$

The map represents the heavy $(\mathrm{H})$ and light $(\mathrm{L})$ strands of the circular mitochondrial genome bearing the genes (solid areas) for the subunits of NADH-dehydrogenase (complex I, $\mathrm{ND}_{1}$ to $\mathrm{ND}_{6}$ ), cytochrome c oxidase I, II and III, ATP-synthetase 6 and 8 (ATPase 6/8) and cytochrome $\mathrm{b}$. The $\mathrm{D}$-loop region and the genes for the small and larger ribosomal RNAs as well as for 22 tRNAs are given as open areas as indicated. $\mathrm{O}_{\mathrm{H}}, \mathrm{O}_{\mathrm{L}}$ are the origins of replication for the heavy and light strand, respectively; $\mathrm{P}_{\mathrm{H} 1}, \mathrm{P}_{\mathrm{H} 2}, \mathrm{P}_{\mathrm{L}}$ mark the respective promotors for the initiation of the heavy and light strand transcription.

Mitochondrial encephalomyopathies are a clinically heterogenous group of neurological disorders characterized histologically by the "ragged red fibres" in muscle. The clinical features include infantile lactic acidosis, Leigh syndrome, chronic progressive external ophthalmoplegia, exercise-induced myopathy and other multisystem disorders. Affection of the central nervous system causes various symptoms like ataxia, blindness, dementia, seizures and stroke-like episodes. Also other organs (heart, kidney, endocrine system) can be affected (24).

Histochemically or biochemically characterized defects of different parts of the respiratory chain are found in the majority of patients with mitochondrial myopathy. As about $20 \%$ of the patients have affected relatives and maternal transmission is much more frequent than paternal transmission it has been suggested that these disorders may be caused by mutation of 
the mitochondrial genome. Using genomic Southern analysis, Holt et al. (1) recently published the first description of deletions of the mtDNA in some forms of mitochondrial myopathies. In the meantime their results have been confirmed by other groups, including our own $(3-12)$.

Treatment of extracted muscular DNA with restriction endonucleases such as PvuII or BamHI, which have only one recognition site in the chronic progressive external ophthalmoplegia genome, usually linearize the mtDNA, resulting in a single band in Southern blots. A possible interference of "mitochondrial" sequences within the nuclear genome can be obviated by short exposure times for the autoradiography, since only high copy number sequences are observable after short time exposure (4). Thus treatment with "single cutter" restriction enzymes and hybridization with labelled total human mtDNA can yield the following patterns (fig. $2 \mathrm{~A}$ ):

- only one single band of expected length, if the genome has no larger deletions, insertions or duplications (fig. 2A, patient $15)$;

- one faster migrating, i. e. smaller DNA, if all mitochondrial genomes are deleted and the deletion is outside the restriction site of the single cutter enzyme;

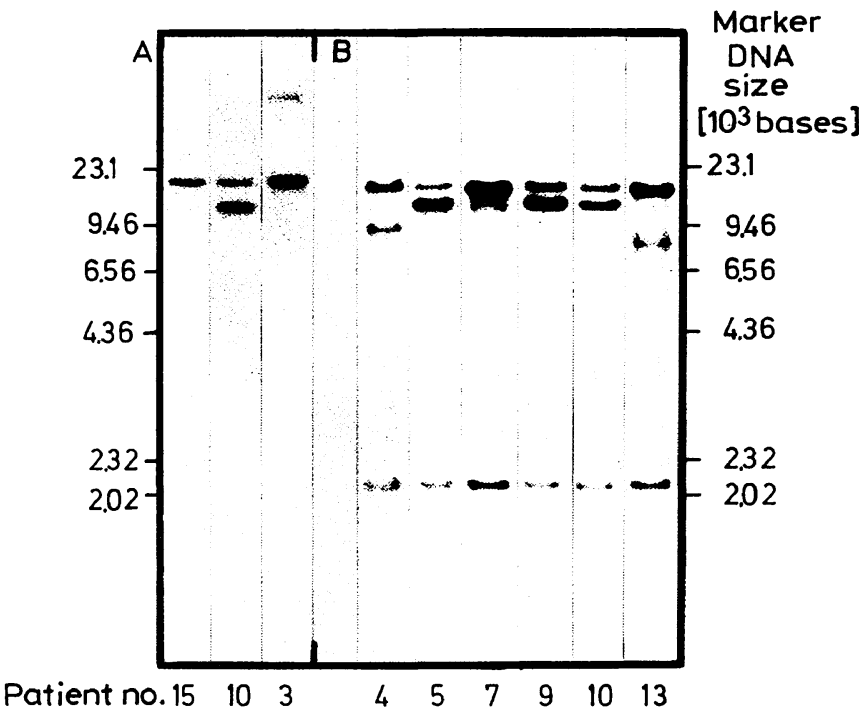

Fig. 2. Autoradiogram of a genomic Southern blot hybridization of muscle mitochondrial DNA from selected patients.

Numbering of patients is the same as in table 1.

A: restriction pattern after digestion with the single cutter enzyme BamHI;

patient 15: only one band of expected size; patient 10: two bands (mtDNA heteroplasmy), one of expected size and one faster migrating smaller band;

patient 3: one band of expected size and one slower migrating band. Further mapping of the mitochondrial genome of patient 3 revealed that the BamHI restriction site was within the deleted part of the genome.

B: restriction pattern after digestion with $P s t \mathrm{I}$, which has two restriction sites within the mitochondrial genome (positions 6910 and 9020); digestion of an intact mitochondrial genome therefore results in two bands, 14487 and 2110 bases in length. Patients 4, $5,7,9,10$ and 13: two bands of expected size with one additional slower migrating band, which demonstrates a deletion in the large restriction fragment. All hybridizations were done using a labelled, nearly full length mtDNA as a probe (12). Marker sizes (in $10^{3}$ bases) are shown at left and right.
- two bands, one of expected size and one more rapidly migrating band, if there are two DNA populations (heteroplasmy) but the restriction site for the single cutter enzyme is not deleted (fig. 2A, patient 10)

- two bands, one of expected size and one slower migrating, if there is mtDNA heteroplasmy and the deletion spans either the restriction site of the single cutter enzyme, resulting in a non-linearized mtDNA population, or there is an insertion within the genome (fig. $2 \mathrm{~A}$, patient 3 ).

\section{Results}

\section{Restriction analysis}

Genomic Southern blotting in 34 patients with different myopathies was performed. When the restriction enzymes, BamHI and PvuII, were used to digest muscular DNA from the 13 patients of group 3 and 4, followed by Southern analysis, a single band of the expected size was found. Thus, there was no mutation involving a lengthy sequence of DNA, i. e. no deletion or insertion, in the muscular mtDNA of these patients. Similarly, no mtDNA deletions were detected in fibroblast cultures from the patients of group 3. DNA samples from all patients of group 3 and 4 were therefore not further investigated. Hybridisation analysis, after digestion with BamHI and PvuII of the muscular DNA from the 21 patients of group 1 and 2 , showed in $13 / 21$ a pattern consistent with two mtDNA populations (mtDNA heteroplasmy); one band corresponded to full-length molecules of mtDNA, while the other, more rapidly migrating band corresponded to smaller, deleted mtDNA. This pattern was found in all 5 patients with the typical Kearns-Sayre triad (25) (group 1) and in 8/16 in group 2 . The remaining 8 patients of group 2 showed a normal pattern and were therefore excluded from further mapping. We cannot exclude however that there were small deletions or even point mutations in these 8 patients. Ten of the 13 patients of group I and II with mitochondrial heteroplasmy were further mapped, using a set of different restriction enzymes (fig. 2B). The site and size of the deletions within the mutated mitochondrial genome are further demonstrated in figure 3. All deletions affected parts of the genes coding for the subunits of complex I of the respiratory chain, and in $9 / 10$ cases the genes for complex IV and V subunits were also involved. In one case only (patient 4 of tab. 1), the gene for cytochrome $b$ (the only mitochondrially encoded complex III subunit) was also affected. In 8 of the 10 mutated mitochondrial genomes (fig. 3) deletion starts within the ATPase 6/8 subunit region, extending to the ND5/6 region. Recently, two independent groups $(26,27)$ demonstrated an identical deletion in KearnsSayre patients. Sequence analysis revealed breakpoints at position 8482 within the ATPase 8 gene and 


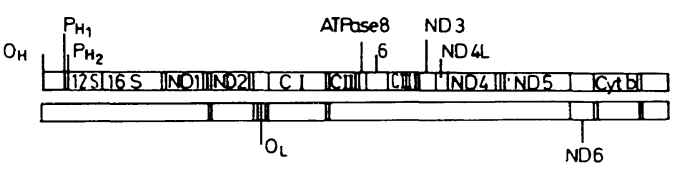

KearnsSayre syndrome

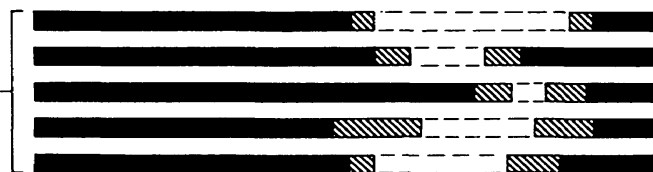

Chronic progressive external ophthalmoplegia

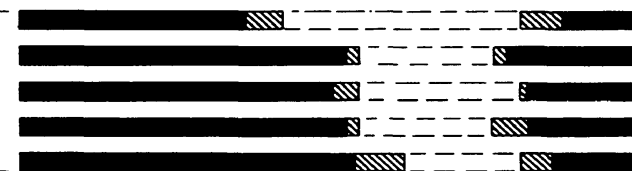

Fig. 3. Localization of mitochondrial DNA deletions in patients with Kearns-Sayre syndrome (group 1) and with ocular myopathy (group 2).

The maps at the top represent the heavy (upper map) and light (lower map) strands of the linearized mtDNA. Symbols are the same as in fig. 1.

Intact regions of the mitochondrial genome are shown as solid areas; the regions of uncertainty as obtained by restriction mapping (12) are indicated as hatched areas; the deletions are given within the dotted lines.

at position 13446 within the ND5 gene. This region is flanked on both sites by a perfect 13 base pair repeat. The 4977 base pair-long deletion spanned one of the repeats. This implies that genomic deletions may arise from homologous recombination in mammalian cells, as already found for other eukaryotic cells (26).

\section{Histochemistry}

A detailed discussion of the extent to which the observed deletions are reflected by histochemical and biochemical measurements in muscle is given elsewhere (12). Here we refer to the diagnostic value of the different methods used. In brief, histochemically we found normal complex II activities in all muscle fibres (not shown in tab. 1), while on the other hand focal deficiency of complex IV was found in all 13 patients with mitochondrial DNA deletions, although in partient 3 (tab. 1) the deletion did not affect mitochondrial complex IV and V genes. Mitochondrial ATP-synthetase was measured histochemically only in 6 out of 13 patients with deleted mitochondrial genomes and was found to be diminished in $4 / 6$.

In 8 of 21 patients with chronic progressive external ophthalmoplegia no large mtDNA deletions were observed. Histochemical determinations were performed in 5 of these 8 patients and cytochrome c oxidase deficiency was found in all 5 patients, while ATPase deficiency was observed in $2 / 5$. Cytochrome c oxidase deficiency was also found histochemically in 4 out of 5 patients of group 3.

\section{Biochemistry}

Biochemical activities of NADH-cytochrome c oxidoreductase (complex I + III), succinate-cytochrome c oxidoreductase (II + III) and cytochrome c oxidase (IV) were determined in 7 out of 13 patients with deleted mtDNA. Although the deletions in all 7 patients affected parts of the complex I genes this genetic situation was reflected by biochemical measurements of complex I + III activities only in 4/7 patients. One patient (No. 1) had decreased complex II + III activity in his muscle, but he had no deletion of the cytochrome b gene. Another patient (No. 4) with a mutated cytochrome $b$ gene exhibited normal complex II activities biochemically as well as histochemically. Only $5 / 7$ patients with a mitochondrial DNA deletion spanning at least parts of the three complex IV genes also had a biochemically deficient cytochrome c oxidase activity in their muscle homogenates.

\section{Discussion}

Similar results (i. e. no clear cut correlation between site and size of the mtDNA deletions at one site and the loss of biochemically measured enzyme activities as well as the severity of the disease at the other site) have also recently been published by other groups ( 4 , $7,38)$. The possible reasons for this lack of a clear correlation are discussed in detail elsewhere (12).

So far, 89 patients with mitochondrial myopathies have been described in the literature $(1-12,38)$, whose mitochondrial DNA exhibits lengthy deletions (tab. 2). All of these had chronic progressive external ophthalmoplegia and all had two populations of mtDNA in their muscle mtDNA (heteroplasmy), with the exception of reference (5).

Taking the results reported so far in the literature (tab. 2) together with our present work, the following conclusions can be drawn.

First, lengthy deletions of the mitochondrial genome were found exclusively in patients with chronic progressive external ophthalmoplegia. Out of 52 patients with the typical Kearns-Sayre triad reported so far, 46 had a mitochondrial heteroplasmy and a population of deleted mtDNA. Poulton et al. (8) reported heteroplasmy and large duplications (about 8000 bases) of the mitochondrial DNA in several tissues of two patients with chronic progressive external ophthalmoplegia. Thus restriction analysis of the mitochondrial genome shows lengthy deletions in about $90 \%$ of Kearns-Sayre patients and about $44 \%$ of all cases with chronic progressive external ophthalmoplegia (tab. 2). 
Tab. 2. Localization of mtDNA deletion and histochemical/biochemical data (group 1, 2, 3)

\begin{tabular}{|c|c|c|c|c|c|c|c|}
\hline \multirow[t]{2}{*}{ Patient no. } & \multicolumn{2}{|l|}{ mtDNA deletions } & \multicolumn{2}{|c|}{$\begin{array}{l}\text { Histochemical } \\
\text { deficiency }\end{array}$} & \multicolumn{3}{|c|}{$\begin{array}{l}\text { Biochemical deficiency } \\
\text { Respiratory chain complex }\end{array}$} \\
\hline & Map coordinates & Affected $\mathrm{mt}$ genes & $\operatorname{cox}$ & ATPase & $\overline{I+I I I}$ & $\mathrm{II}+\mathrm{III}$ & IV \\
\hline \multicolumn{8}{|l|}{ Group 1} \\
\hline $\begin{array}{l}1 \\
2 \\
3 \\
4 \\
5\end{array}$ & $\begin{array}{r}8286-14956 \\
9000-13000 \\
11680-14747 \\
7867-14956 \\
8286-13367\end{array}$ & $\begin{array}{l}\text { A } 8-\text { ND } 6 \\
\text { A } 5-\text { ND } 5 \\
\text { ND } 4-\text { ND } 6 \\
\text { COX II - Cytb } \\
\text { A } 8-\text { ND } 5\end{array}$ & $\begin{array}{l}+ \\
+ \\
+ \\
+ \\
+\end{array}$ & $\begin{array}{l}\text { n.d. } \\
\text { n.d. } \\
\text { n.d. } \\
\text { n.d. } \\
+\end{array}$ & $\begin{array}{l}+ \\
\emptyset \\
\emptyset \\
+\end{array}$ & $\begin{array}{l}+ \\
\emptyset \\
\emptyset \\
\emptyset \\
\text { n.d. }\end{array}$ & $\begin{array}{l}+ \\
+ \\
\emptyset \\
+\end{array}$ \\
\hline \multicolumn{8}{|l|}{ Group 2} \\
\hline $\begin{array}{r}6 \\
7 \\
8 \\
9 \\
10 \\
11 \\
12 \\
13 \\
14 \\
15 \\
16 \\
17 \\
18 \\
19 \\
20 \\
21\end{array}$ & $\begin{array}{r}6070-14258 \\
8640-13020 \\
8286-13520 \\
8640-13667 \\
8867-14258 \\
\text { deletion not mapped } \\
\text { not mapped } \\
\text { not mapped } \\
\text { no larger mt deletion } \\
\text { no larger mt deletion } \\
\text { no larger mt deletion } \\
\text { no larger mt deletion } \\
\text { no larger mt deletion } \\
\text { no larger } \mathrm{mt} \text { deletion } \\
\text { no larger } \mathrm{mt} \text { deletion } \\
\text { no larger } \mathrm{mt} \text { deletion }\end{array}$ & $\begin{array}{l}\text { COX I - ND } 6 \\
\text { A } 6-\text { ND } 5 \\
\text { A } 8 \text { - ND } 5 \\
\text { A } 6-\text { ND } 5 \\
\text { A } 6-\text { ND } 6\end{array}$ & $\begin{array}{l}+ \\
+ \\
+ \\
+ \\
+ \\
+ \\
+ \\
+ \\
+ \\
+ \\
+ \\
\text { n.d. } \\
\text { n.d. }\end{array}$ & $\begin{array}{l}\emptyset \\
+ \\
\text { n.d. } \\
\text { n.d. } \\
\text { n.d. } \\
+ \\
\emptyset \\
+ \\
+ \\
\emptyset \\
\emptyset \\
\text { n.d. } \\
+ \\
\emptyset \\
\text { n.d. } \\
\text { n.d. }\end{array}$ & $\begin{array}{l}\emptyset \\
+ \\
+\end{array}$ & $\begin{array}{c}\text { n.d. } \\
\text { n.d. } \\
\text { n.d. } \\
\emptyset \\
\emptyset \\
\emptyset \\
\text { n.d. } \\
\text { n.d. } \\
\text { n.d. } \\
\text { n.d. } \\
\emptyset \\
\emptyset \\
\text { n.d. } \\
\text { n.d. } \\
\text { n.d. } \\
\text { n.d. } \\
\text { n.d. }\end{array}$ & $\begin{array}{l}\emptyset \\
+ \\
+\end{array}$ \\
\hline \multicolumn{8}{|l|}{ Group 3} \\
\hline $\begin{array}{l}22 \\
23 \\
24 \\
25 \\
26\end{array}$ & $\begin{array}{l}\text { no larger } \mathrm{mt} \text { deletion } \\
\text { no larger } \mathrm{mt} \text { deletion } \\
\text { no larger } \mathrm{mt} \text { deletion } \\
\text { no larger } \mathrm{mt} \text { deletion } \\
\text { no larger } \mathrm{mt} \text { deletion }\end{array}$ & & $\begin{array}{l}+ \\
+ \\
+ \\
\text { n.d. } \\
+\end{array}$ & $\begin{array}{l}\text { n.d. } \\
\text { n.d. } \\
\emptyset \\
\text { n.d. } \\
\emptyset\end{array}$ & $\begin{array}{l}+ \\
\emptyset \\
\emptyset \\
+ \\
\emptyset\end{array}$ & $\begin{array}{l}\emptyset \\
\emptyset \\
\emptyset \\
\emptyset\end{array}$ & $\begin{array}{l}+ \\
+ \\
+ \\
+ \\
\emptyset\end{array}$ \\
\hline
\end{tabular}

ND $1-6$, subunits of NADH-dehydrogenase (complex I)

A $6 / 8$, ATPase subunit 6 and 8 , respectively

COX, cytochrome c oxidase

$\emptyset$, normal pattern (histochem.), no deficiency (biochem.)

+ , focal deficiency (histochem.), decreased enzyme activity (biochem.)

n. d., not determined

Respiratory chain complexes I + III, II + III, IV, for biochemical measurements see the method section

Secondly, no lengthy deletions of the mtDNA have so far been detected by restriction analysis in other defined mitochondrial myopathies or encephalomyopathies, such as myopathies with lactic acidosis, benign or fatal infantile cytochrome c oxidase deficiency, Luft's disease, mitochondrial encephalomyopathy with lactic acidosis and stroke-like episodes, myoclonus epilepsy with ragged red fibers (with the exception of 1.c. (5)) and others. Wallace (28) presented considerable evidence for small mtDNA deletions in myoclonus epilepsy with ragged red fibers. A point mutation was observed in cases with Leber's opticus atrophy (29).

Thirdly, usually a normal pattern for complex II activity was found histochemically in muscles from patients with chronic progressive external ophthalmoplegia, with the exception of 1.c. (30). Exact histochemical determination of NADH-dehydrogenase is impossible, because the rotenone-sensitive (complex
I) and rotenone-insensitive activities (microsomal fraction) cannot be separated by this technique. Focal deficiency of complex IV activity was found in the majority of patients with chronic progressive external ophthalmoplegia, but also in patients suffering from other forms of mitochondrial myopathy, indicating defects in the nuclear-mitochondrial axis. Histochemical determination of cytochrome $\mathrm{c}$ oxidase therefore seems to be a good screening method for all forms of mitochondrial myopathy involving the respiratory chain. ATPase activity was found to be deficient in about $30-50 \%$ of the patients with mtDNA deletions.

Fourthly, biochemical measurements of the different complexes of the respiratory chain yielded decreased activity only in $30-50 \%$ of patients with a deleted mitochondrial genome. This is probably due to the fact that in Kearns-Sayre syndrome and related disorders focal defects affecting only single fibres are 
common. Overall activity measurements in tissue homogenates might therefore not reflect the situation, because the number of affected cells is to small. Biochemical measurements in muscle homogenates from patients with chronic progressive external ophthalmoplegia are therefore of minor diagnostic value.

Fifthly, as can be seen from table 2, in more than 50 percent of patients with chronic progressive external ophthalmoplegia, restriction fragment analysis did not detect any large mtDNA deletions. However this does not necessarily mean that there were no mtDNA mutations in these patients. For methodical reasons detection of mutations by genomic Southern blotting depends on a given length of the mutation (about 200 base pairs) and on a given number of mutated genomes (about $5 \%$ of total mtDNA). If neither parameter attains its necessary value, restriction analysis will yield false negative results. A convincing example for this fact was given most recently by Sato et al. (10). Using a primer shift polymerase chain reaction the authors were able to demonstrate seven populations of differently deleted mtDNA $(3.9-5.2 \mathrm{~kb}$ in length) in a patient with chronic progressive external ophthalmoplegia. In this patient a normal BamHI and PvuII restriction pattern was found, his isolated muscle mitochondria showed normal activities for all respiratory chain complexes, and the Western blot analysis of several subunits of the respiratory chain complexes yielded a normal pattern. The authors noted that the history of the patient's family suggested maternal transmission of the disease.

Sixthly, the question of whether the large mtDNA deletions found in patients with chronic progressive external ophthalmoplegia are maternally transmitted, i. e. inherited, or indeed genetic, but aquired during the early state of development is of major importance for genetic counselling. All of our 13 patients with mtDNA deletions were singleton cases, while three patients of group 2 without a mutated mitochondrial genome had affected family members. Out of the 21 chronic progressive external ophthalmoplegia patients with mtDNA heteroplasmy reported by Holt et al. (1, 2,38 ) only two had a similarly affected relative, while 10 of their patients without deletions had clinically affected family members, and maternal transmission occurred in $50 \%$. None of the 32 chronic progressive external ophthalmoplegia cases with mtDNA deletion described by Moreas et al. (7) had affected family members, whereas approximately half $(13 / 27)$ the patients with ocular myopathy but without detectable mtDNA deletions had. Thus it seems evident that the majority of chronic progressive external ophthalmoplegia patients with mtDNA deletions detectable by restriction analysis and Southern botting are spontaneous singleton cases. There are three reports $(4,10$, 31) dealing with inheritance of larger mtDNA deletions. Ozawa et al. (4) described maternal inheritance of non-identical mtDNA deletions in a mother/daughter pair. The same group reported (10) the case mentioned above with deletions only demonstrable after amplification of the mitochondrial genome using the polymerase chain reaction. Zeviani et al. (31) in a most recent paper demonstrated an autosomal dominant disorder with multiple deletions of mtDNA in a large Italian family suffering from late-onset mitochondrial myopathy, including chronic progressive external ophthalmoplegia, progressive proximal weakness, bilateral cataract and precocious death. This report demonstrated in an impressive way the close cooperation between the nuclear genome and the mtDNA in order to establish the highly organized structure of the respiratory chain complexes.

As Kearns-Sayre syndrome and related diseases are multisystem disorders the mtDNA deletions may not be confined to skeletal muscle alone, but may affect other tissues. Similar deletions to those in muscle have been found in single cases in brain, liver, spinal cord, primary fibroblasts and myoblast cultures as well as in white blood cells $(9,11,32,33)$. While we were able to detect an identical deletion, i. e. of equal size and site, in skeletal muscle, heart, liver and kidney in one Kearns-Sayre patient (34), we could find no corresponding mutations in fibroblast cultures or in white blood cells from two others. Holt et al. $(1,2,38)$ were also unable to find deletions in the mtDNA of leukocytes from their patients with deleted muscular mitochondrial genome. This discrepancy or uneven distribution of affected mitochondrial genomes in different tissues might be due to mitotic segregation (23) during the early state of development of the oocyte or the zygote, resulting in quite different proportions of deleted genomes in the different tissues. Furthermore, the method of restriction analysis might not be sensitive enough to detect small proportions of deleted mtDNA. Amplification of the "hot spot" regions within the mitochondrial genome by the polymerase chain reaction $(26,27,35)$ will probably solve the question of whether white blood cells or fibroblasts could serve for diagnosis.

\section{Diagnostic procedures}

With respect to the limited tissue material usually available and taking into consideration the data in the literature, we propose the diagnostic procedure given in figure 4 . The main conclusions regarding the choice of diagnostic procedure are set out below. 


\section{Diagnostic procedures for mitochondrial disorders}

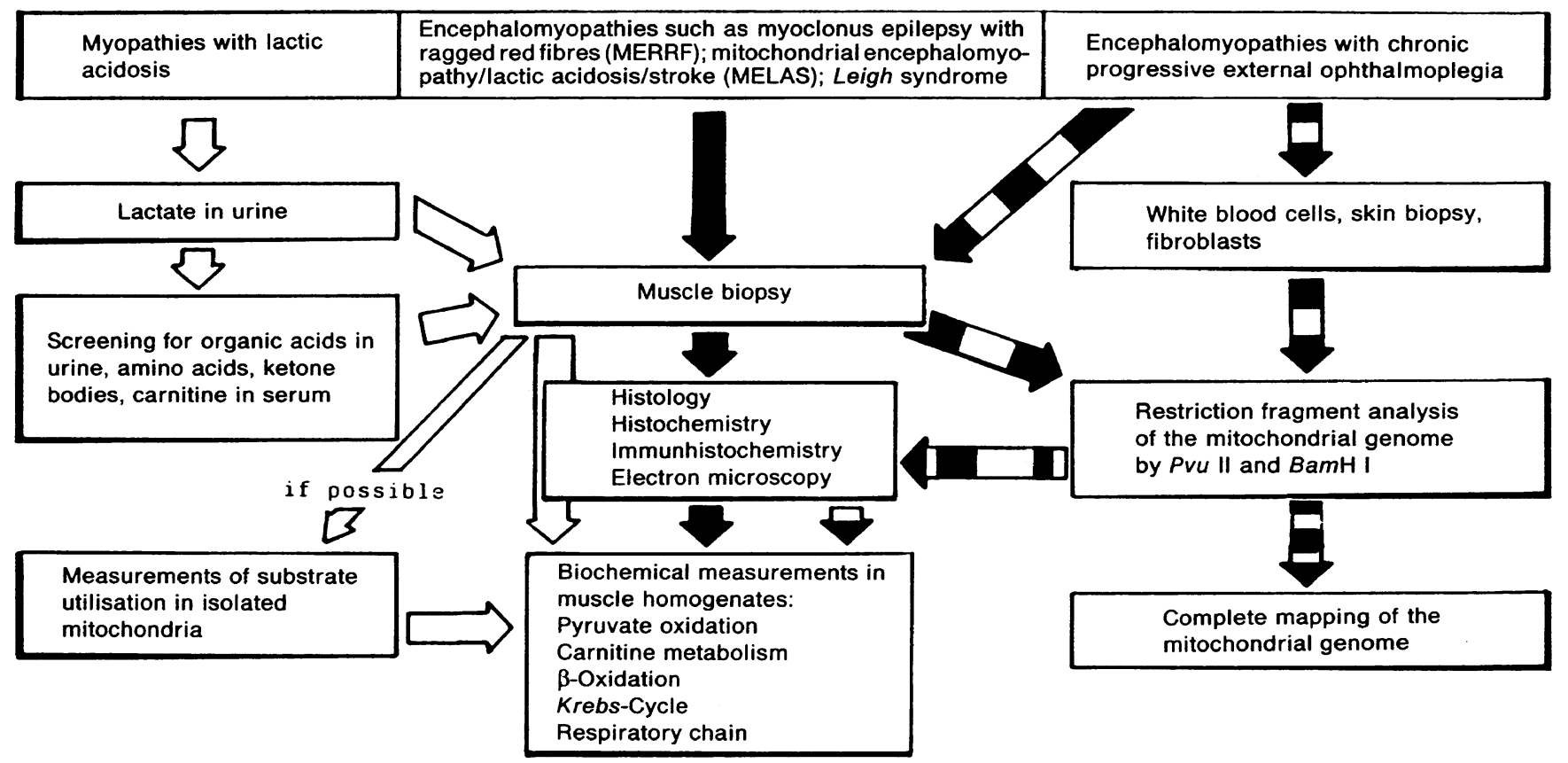

Fig. 4. Diagnostic procedures for mitochondrial disorders.

Tab. 3. Summary of muscular mtDNA deletions reported so far: update January 1990

\begin{tabular}{|c|c|c|c|c|}
\hline $\begin{array}{l}\text { Classification of disease } \\
\text { (reference) }\end{array}$ & $\begin{array}{l}\text { Total number } \\
\text { of patients }\end{array}$ & $\begin{array}{l}\text { Patients with } \\
\text { mtDNA heteroplasmy } \\
\text { in muscle }\end{array}$ & $\begin{array}{l}\text { Patients with } \\
\text { mtDNA heteroplasmy } \\
\text { and familial history }\end{array}$ & $\begin{array}{l}\text { Patients without } \\
\text { mtDNA heteroplasmy } \\
\text { and familial history }\end{array}$ \\
\hline
\end{tabular}

Kearns-Sayre syndrome (chronic progressive external ophthalmoplegia, retinitis pigmentosa, + one additional symptom)

$\begin{array}{lrr}(1,2,38) & 10 & 8 \\ (11) & 11 & 11 \\ (7) & 18 & 15 \\ (33) & 7 & 6 \\ (8) & 1 & 1 \\ (12, \text { this study) } & \frac{5}{52} & \frac{5}{46}\end{array}$

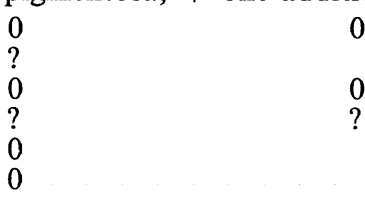

Ocular myopathy (without Kearns-Sayre syndrome)

$\begin{array}{lrr}(1,2,38) & 32 & 12 \\ (7) & 44 & 17 \\ (6) & 2 & 2 \\ (8) & 2 & 2 \\ (9) & 2 & 1 \\ (10) & 2 & 1 \\ (12, \text { this study) } & \underline{16} & \frac{8}{43}\end{array}$

Other mitochondrial myopathies*)

$\begin{array}{lr}(1,2,38) & 30 \\ (7) & 61 \\ (5) & 1 \\ \text { (this study) } & \frac{5}{97}\end{array}$

*) including: myoclonus epilepsy with ragged red fibres, mitochondrial encephalomyopathy/lactic acidosis/stroke, Leigh syndrome, congenital lactic acidosis, benign and fatal cytochrome c oxidase deficiency, ATPase deficiency and other diseases without chronic progressive external ophthalmoplegia 
- For exact defect localization, restriction analysis and mapping of muscular mtDNA is superior to histological, histochemical and biochemical methods in patients with chronic progressive external ophthalmoplegia. The latter methods provide confirmatory evidence. In chronic progressive external ophthalmoplegia cases with a family history of the disease, if the restriction analysis using single cutter restriction endonucleases gives a negative result, the mitochondrial genome fragments should be amplified by the polymerase chain reaction. The same is true for other mitochondrial disorders with maternal transmission, where restriction analysis of the mtDNA so far failed to detect any mutations. DNA techniques, which allow the detection of small or even point mutations have been successfully applied in cases with Leber's opticus atrophy (29), and these should also be used for other patients.

- Histological, histochemical, immunological and biochemical determinations are the methods of choice for the time being for all spontaneous singleton cases suffering from mitochondrial myopathies with lactic acidosis as the leading symptom, since DNA techniques at the level of the nuclear genome are still in their infancy. With respect to the tissue specificity of certain mitochondrial diseases, the existence and the investigation of nuclear encoded isoforms, for example of cytochrome c oxidase (36), will be of special interest.

A closer cooperation between clinicians, biochemists and molecular biologists is necessary in the near future, in order to develop successful diagnostic procedures for the different forms of mitochondrial disorders. As noted by Wallace (87), a wide spectrum of neuromuscular diseases has been shown to be influenced by maternal factors. DNA techniques will undoubtedly soon identify other mtDNA genetic diseases, ultimately replace biochemical and histochemical procedures and lead to a better understanding of the underlying principles of genetic mitochondrial disorders.

\section{References}

1. Holt, I. J., Harding, A. E. \& Morgan-Hughes, J. A. (1988) Deletions of muscles mitochondrial DNA in patients with mitochondrial myopathies. Nature 331, 717-719.

2. Holt, I. J., Cooper, I. M., Morgan-Hughes, I. A. \& Harding, A. E. (1988) Deletions of muscle mitochondrial DNA. Lancet $i i, 1462$.

3. Lestienne, P. \& Ponsot, G. (1988) Kearns-Sayre syndrome with muscle mitochondrial DNA deletion. Lancet $i, 885$.

4. Zeviani, M., Moraes, C. T., Di Mauro, S., Nakase, H., Bonilla, E., Schon, E. A. \& Rowland, L. P. (1988) Deletions of the mitochondrial DNA in Kearns-Sayre syndrome. Neurology 38, 1339-1346.

5. Saifuddin Noer, A., Marzuki, S., Trounce, I. \& Byrne, E. (1988) Mitochondrial DNA deletion in encephalomyopathy. Lancet $i i, 1253-1254$.

6. Ozawa, T., Yoneda, M., Tanaka, M., Ohno, K., Sato, W., Suzuki, H., Nishikimi, M., Yamamoto, M., Nonaka, I. \& Horai, S. (1988) Maternal inheritance of deleted mitochondrial DNA in a family with mitochondrial myopathy. Biochem. Biophys. Res. Comm. 154, 1240-1247.

7. Moraes, C. T., Di Mauro, S., Zeviani, M., Lombes, A., Shanske, S., Miranda, A. F., Nakase, H., Bonilla, E., Werneck, L. C., Servidei, S., Nonaka, I., Koga, Y., Spiro, A. J., Brownell, K. W., Schmidt, B., Schotland, D. L., Zupanc, M., de Vivo, D. C., Schon, E. A. \& Rowland, L. P. (1989) Mitochondrial DNA deletions in progressive external ophthalmoplegia and Kearns-Sayre syndrome. N. Engl. J. Med. 320, 1293-1299.

8. Poulton, I., Deadman, M. E. \& Gardiner, R. M. (1989) Duplications of mitochondrial DNA in mitochondrial myopathy. Lancet $i, 236-239$.

9. Johns, D. R., Drachman, D. B. \& Hurko, O. (1989) Identical mitochondrial DNA deletions in blood and muscle. Lancet $i, 393-394$.
10. Sato, W., Tanaka, M., Ohno, K., Yamamoto, T., Takada, G. \& Ozawa, T. (1989) Multiple populations of deleted mitochondrial DNA detected by a novel gene amplification method. Biochem. Biophys. Res. Comm. 162, 664-672.

11. Nelson, I., Degoul, F., Obermaier-Kusser, B., Romero, N., Borrone, C., Marsac, C., Vaysierre, J. L., Gerbitz, K.-D., Fardeau, M., Ponsot, G. \& Lestienne, P. (1989) Mapping of heteroplasmic mitochondrial DNA deletions in KearnsSayre syndrome. Nucl. Acids Res. 17, 8117-8124.

12. Gerbitz, K.-D., Obermaier-Kusser, B., Zierz, S., Pongratz, D., Müller-Höcker, J. \& Lestienne, P. (1990) Mitochondrial myopathies: divergence of genetic deletions, biochemical defects and the clinical syndromes. J. Neurology, in press.

13. Dubowitz, V. (1985) Muscle biopsy: A practical approach. Balliere Tindall, London.

14. Yorifugi, S., Ogasahara, S., Takanashi, M. \& Tarui, S. (1985) Decreased activities in mitochondrial inner membrane electron transport system in muscle from patients with Kearns-Sayre syndrome. J. Neurol. Sci. 71, 65-75.

15. Hatefi, Y. \& Rieske, I. S. (1967) The preparation and properties of DPNH-cytochrome-c-reductase (complex I-III of the respiratory chain). Methods Enzymol. 10, $225-231$.

16. Tisdal, H. D. (1967) Preparation and proportions of succinic-cytochrome reductase (complex II - III). Methods Enzymol. 10, 213-215.

17. Hatefi, Y. \& Stiggall, I. S. (1978) Preparation and properties of succinate: ubichinone oxido-reductase (complex II). Methods Enzymol. 53, 21-27.

18. Wharton, D. C. \& Tzagaloff, A. (1967) Cytochrome c oxidase from beef heart mitochondria. Methods Enzymol. $10,245-250$.

19. Sheperd, D. \& Garland, P. B. (1969) Citrate synthase from rat liver. Methods Enzymol. 13, 11-16. 
20. Maniatis, T., Fritsch, E. F. \& Sambrook, I. (1982) Molecular cloning, Cold Spring Harbor. Laboratory Press, Cold Spring Harbor, N. Y.

21. Drouin, I. (1980) Cloning of human mitochondrial DNA in Escherichia coli. J. Mol. Biol. 140, 341.

22. Anderson, S., Bankler, A. T., Barek, B. G., de Brujin, M. H. L., Coulson, A. R., Drouin, I., Eperon, I. C., Nierlich, P. D., Roe, B. A., Sanger, F., Schreier, P. H., Smith, A. I. H., Staden, R. \& Young, I. G. (1981) Sequence and organization of the human mitochondrial genome. Nature 290 , $457-465$.

23. Wallace, D. C. (1987) Maternal genes: mitochondrial diseases. Birth Defects 23, 137-190.

24. Petty, R. K. H., Harding, A. E. \& Morgan-Hughes, J. A. (1986) The clinical features of mitochondrial myopathy. Brain 109, 915-938.

25. Kearns, T. P. \& Sayre, G. P. (1958) Retinitis pigmentosa, external ophthalmoplegia and complete heart block. Archives Opthalmol. Am. Med. Ass. 60, 280-289.

26. Schon, E. A., Rizzuto, R., Moraes, C. T., Nakase, H., Zeviani, M. \& DiMauro, S. (1989) A direct repeat is a hotspot for large-scale deletion of human mitochondrial DNA. Science 244, 346-349.

27. Holt, I. J., Harding, A. E. \& Morgan-Hughes, J. A. (1989) Deletions of muscle mitochondrial DNA in mitochondrial myopathies: sequence analysis and possible mechanisms. Nucl. Acids Res. 17, 65-68.

28. Wallace, D. C., Zheng, X., Lott, M. T., Shoffner, J. M., Hodge, J. A., Kelley, R. I., Epstein, C. M. \& Hopkins, L. C. (1988) Familial mitochondrial encephalomyopathy (MERRF): genetic pathophysiological and biochemical characterization of a mitochondrial DNA disease. Cell 55, $601-610$

29. Singh, G., Loff, M. T. \& Wallace, D. C. 8 (1989) A mitochondrial DNA mutation as a cause of Leber's hereditary optic neuropathy. N. Engl. J. Med. 320, 1300-1305.

30. Rivner, M. H., Shamsnia, M., Swift, T. R., Trefz, J., Roesel, R. A., Carter, A. L., Yanamura, W. \& Hommes, F. A. (1989) Kearns-Sayre syndrome and complex II deficiency. Neurology 39, 693-696.
31. Zeviani, M., Servidei, S., Gellera, C., Bertini, E., Di Mauro, S. \& Di Donato, S. (1989) An autosomal dominant disorder with multiple deletions of mitochondrial DNA starting at the D-loop region. Nature 339, 309-311.

32. Moraes, C. T., Schon, E. A., Di Mauro, S. \& Miranda, A. F. (1989) Heteroplasmy of mitochondrial genomes in clonal cultures from patients with Kearns-Sayre syndrome. Biochem. Biophys. Res. Comm. 160, 765-771.

33. Bresolin, N., Moggio, M., Bet, L., Meola, G. \& Scarlato, G. (1989) Mitochondrial DNA deletions in mitochondrial myopathies and genetic analysis in two families presenting partial COX deficiency. Workshop on "Molecular genetics and noninvasive diagnostic technology in mitochondrial myopathies" (abstract). Orsay, France.

34. Obermaier-Kusser, B., Müller-Höcker, J., Riedele, Th. \& Gerbitz, K.-D. (1990) Same heteroplasmy of mitochondrial DNA in different tissue from a patient with Kearn-Sayre syndrome; tissue specific threshold of mitochondrial deletions for changes in the protein content might depend on nuclear genes. Biochem. Biophys. Res. Comm., submitted.

35. Saiki, R. K., Gelfand, D. H., Stoffel, S., Scharf, S. I., Higuchi, R., Horn, G. T., Mullis, K. B. \& Ehrlich, H. A. (1988) Primer-directed enzymatic amplification of DNA with a thermostable DNA polymerase. Science $239,487-$ 491.

36. Suske, G., Enders, C., Schlerf, A. \& Kadenbach, B. (1988) Organization and nucleotide sequence of two chromosomal genes for rat cytochrome coxidase subunit VIC: a structural and processed gene. DNA 7, 163-171.

37. Wallace, D. C. (1989) Mitochondrial DNA mutations and neuromuscular disease. Trends in Genetics 5, 9-13.

38. Holt, I. J., Harding, A. E., Cooper, J. M., Schapira, A. H. V., Toscana, A., Clark, J. B. \& Morgan-Hughes, J. A. (1989) Mitochondrial Myopathies: Clinical and Biochemical Features of 30 Patients with Major Deletions of Muscle Mitochondrial DNA. Ann. Neurology 26, 699-708.

Prof. Dr. K.-D. Gerbitz

Institut für Klinische Chemie

Städt. Krankenhaus Schwabing

Kölner Platz 1

D-8000 München 40 